\title{
A segmented modified look-locker inversion recovery (MOLLI) sequence for high heart rate T1 mapping of mice
}

\author{
Maryam Nezafat ${ }^{1,3^{*}}$, Markus Henningsson ${ }^{1}$, Christian Stehning ${ }^{2}$, Mehmet Akcakaya ${ }^{3}$, Andrea Protti ${ }^{1}$, Rene Botnar ${ }^{1}$ \\ From 18th Annual SCMR Scientific Sessions \\ Nice, France. 4-7 February 2015
}

\section{Background}

Quantitative $T_{1}$ mapping provides myocardial tissue characterization for assessment of various cardiomyopathies. The Modified Look-locker (MOLLI) sequence is widely used for mapping the $T_{1}$ quantification, where multiple single-shot images are acquired along the $\mathrm{T}_{1}$ recovery curve after an inversion pulse. However, single-shot imaging becomes infeasible for mouse imaging at high heart rates due to motion artifacts and requirements of resolution/coverage. Additionally, typical MOLLI sampling schemes [1] (3-3-5) and the pauses between blocks have to be adapted to the high heart rates in mice. In this work, we propose a segmented acquisition scheme for $T_{1}$ mapping of mouse at high heart rates. After an initial inversion pulse we acquire segments for 20 images in subsequent heartbeats followed by 20 pause heartbeats to allow for full magnetization recovery. The complete k-space is acquired in this fashion over 5 segments per image. Experiments were performed with a $T_{1}$ phantom by simulating high heart rates to evaluate the accuracy of the proposed sequence. Proof of concept T1 maps were also acquired in one healthy mouse.

\section{Methods}

The proposed pulse sequence scheme is illustrated in Figure 1, which consists of a segmented ECG-triggered MOLLI sequence with 20 acquisitions and 20 pauses, which were adapted to the high heart rates. Imaging was performed on a 1.5T Philips Achieva (Philips, Best, The Netherlands) scanner using a 32-element cardiac coil. The phantom consists of 14 vials with $\mathrm{T}_{1}$ values ranging from 200 to $1500 \mathrm{~ms}$. Data acquisition consisted of a SSFP sequence with the following parameters: $T R=2.6 \mathrm{~ms}$,

${ }^{1}$ Kings college London, London, UK

Full list of author information is available at the end of the article

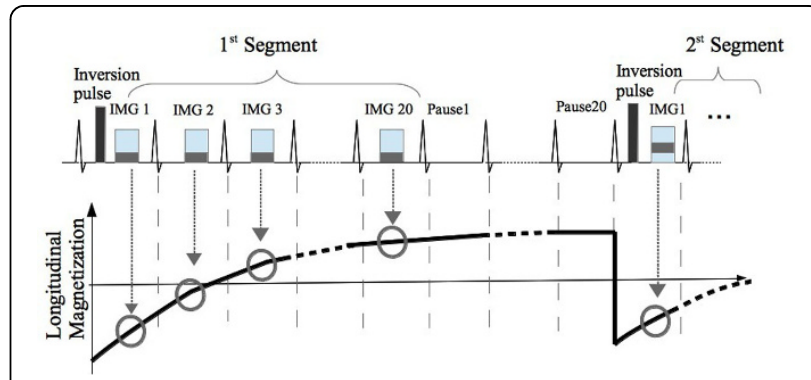

Figure 1 segmented ECG trigger MOLLI sequence with 20 acquisitions and 20 pauses. Images were acquired with enddiastole trigger delay. The $T_{1}$ mapping was performed online.

$\mathrm{TE}=1.3 \mathrm{~ms}$, flip angle $=20^{\circ}$, in-plane resolution $=2 \times 2 \mathrm{~mm}^{2}$, FOV $=210 \times 137 \mathrm{~mm}^{2}$. A simulated ECG signal with heart rates of 60, 100, 250, 300 and 400bpm was used. For reference, an inversion recovery spin-echo sequence with 16 different inversion times between 50 and 3000 were used. In vivo mouse imaging was also performed to demonstrate the feasibility of the sequence.

\section{Results}

Figure $2 \mathrm{~A}$ shows the measured $\mathrm{T}_{1}$ with the spin echo and the segmented MOLLI technique for a heart rate of $300 \mathrm{bpm}$. The proposed sequence underestimated $\mathrm{T}_{1}$ with respect to the spin echo $(\mathrm{p}=0.3)$, but the difference was non-significant. For short $\mathrm{T}_{1}$ the relative difference between the reference and segmented MOLLI is 0.5-4.1\% and for long $\mathrm{T}_{1}$ it is $7.1-10 . \%$ for a heart rate of $300 \mathrm{bpm}$. Figure $2 \mathrm{~B}$ shows results of vials with short, intermediate and long $\mathrm{T} 1$ values that were determined with both methods. For higher heart rates the relative difference between the proposed method and reference was relatively small $(p=0.3)$. Figure $2 \mathrm{C}$ is a representative in-vivo T1 map image in a mouse acquired with a heart rate of $310 \mathrm{bpm}$. 
A)

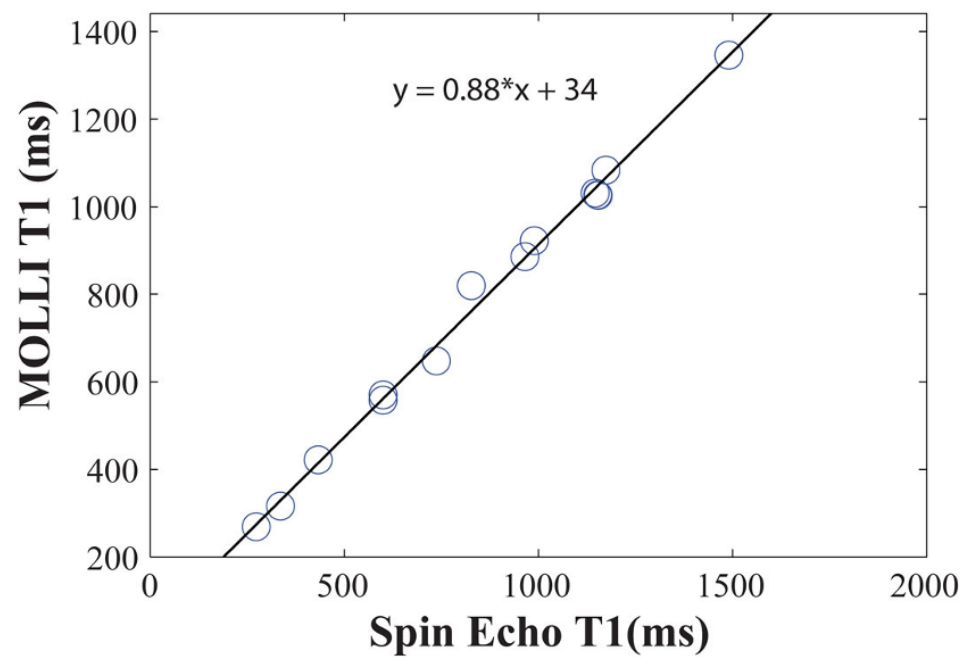

B)

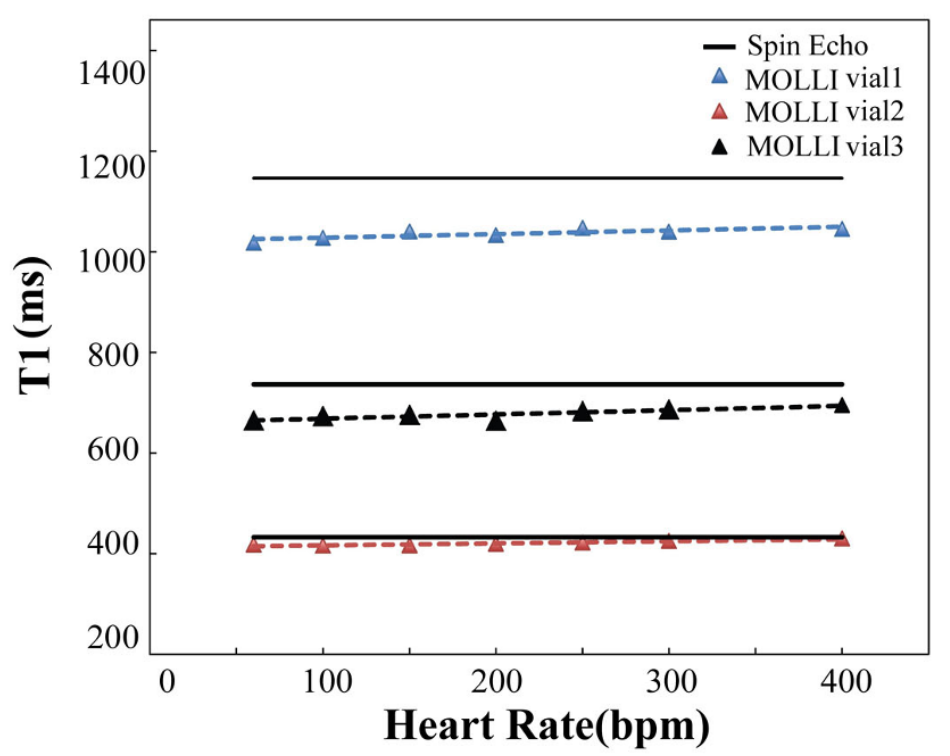

C)

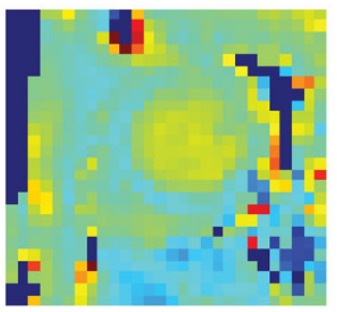

2000

1000

Figure 2 A) Regression analysis of the MOLLI for heart rate of 300 bpm and flip angle 20 $0^{\circ}$ B) T1 time of 3 vials of the phantom calculated with SE and MOLLI at various heart rates. The measured T1 shows an underestimation, which is less pronounced at high rates $\left(R^{2}>0.8\right)$. C) T1 map. The measured $\mathrm{T} 1$ of the myocardium is $792.9 \pm 95.1$. 


\section{Conclusions}

We demonstrate the feasibility of $T_{1}$ mapping for high heart rates observed in mice. The proposed segmented MOLLI sequence provides accurate $T_{1}$ estimates for short $\mathrm{T}_{1}$ values, while an underestimation is observed for higher $T_{1}$ values, as typical of MOLLI.

\section{Funding}

British Heart Foundation : RG/12/1/29262.

\section{Authors' details}

'Kings college London, London, UK. ${ }^{2}$ Philips Research, Hamburg, Germany. ${ }^{3}$ Medicine, Beth Israel Deaconess Medical Centre an Harvard Medical School, Boston, MA, USA.

Published: 3 February 2015

\section{Reference}

1. Messroghli : Radiology 2011.

doi:10.1186/1532-429X-17-S1-P120

Cite this article as: Nezafat et al: A segmented modified look-locker

inversion recovery (MOLLI) sequence for high heart rate T1 mapping of mice. Journal of Cardiovascular Magnetic Resonance 2015 17(Suppl 1):P120.

Submit your next manuscript to BioMed Central and take full advantage of:

- Convenient online submission

- Thorough peer review

- No space constraints or color figure charges

- Immediate publication on acceptance

- Inclusion in PubMed, CAS, Scopus and Google Scholar

- Research which is freely available for redistribution

Submit your manuscript at www.biomedcentral.com/submit
C Biomed Central 